Volume 5

Issue 4 -- Patient Self-Management

Article 5

$10-29-2018$

\title{
Patient Barriers for Weight Management Among African American Women
}

\author{
Owen Bowie \\ Jennifer Kusch \\ George L. Morris III \\ Tracy Flood \\ Jessica Gill \\ Renee E. Walker \\ Ron A. Cisler \\ Jennifer T. Fink
}

Follow this and additional works at: https://aah.org/jpcrr

Part of the Behavioral Medicine Commons, Community Health and Preventive Medicine Commons, Health Services Research Commons, Primary Care Commons, Public Health Education and Promotion Commons, and the Women's Health Commons

\section{Recommended Citation}

Bowie O, Kusch J, Morris GL 3rd, Flood T, Gill J, Walker RE, Cisler RA, Fink JT. Patient barriers for weight management among African American women. J Patient Cent Res Rev. 2018;5:287-97. doi: 10.17294/ 2330-0698.1643

Published quarterly by Midwest-based health system Advocate Aurora Health and indexed in PubMed Central, the Journal of Patient-Centered Research and Reviews (JPCRR) is an open access, peer-reviewed medical journal focused on disseminating scholarly works devoted to improving patient-centered care practices, health outcomes, and the patient experience. 


\title{
Patient Barriers for Weight Management Among African American Women
}

\author{
Owen Bowie, MPH, ${ }^{1}$ Jennifer Kusch, PhD, ${ }^{2,3}$ George L. Morris, III, MD, ${ }^{3,4}$ Tracy Flood, MD, PhD, ${ }^{5}$ \\ Jessica Gill, BA, ${ }^{1}$ Renee E. Walker, DrPH, ${ }^{6}$ Ron A. Cisler, PhD, ${ }^{7}$ Jennifer T. Fink, $\mathrm{PhD}^{1}$ \\ ${ }^{1}$ College of Health Sciences, University of Wisconsin-Milwaukee, Milwaukee, WI; ${ }^{2}$ School of Health Sciences, \\ Milwaukee Area Technical College, Milwaukee, Wl; ${ }^{3}$ Center for Urban Population Health, Milwaukee, WI; ${ }^{4}$ Ascension \\ Columbia St. Mary's Hospital Milwaukee, Milwaukee, WI; ${ }^{5}$ BroadStreet Health LLC, Milwaukee, WI; ${ }^{6}$ Joseph J. Zilber \\ School of Public Health, University of Wisconsin-Milwaukee, Milwaukee, WI; ${ }^{7}$ College of Health and Human Services, \\ Western Michigan University, Kalamazoo, MI
}

Purpose $\quad$ The primary aim of this study was to assess the perceptions of local African American women who are overweight or obese using semi-structured focus groups to identify barriers to weight management and factors that support strategy success. The secondary aim of this study was to determine recommendations for patient-centered weight management interventions established specifically for African American women in the Milwaukee-area community.

Methods Three semi-structured focus groups to explore barriers to weight management were performed among women patients. Participants $(\mathrm{N}=41)$ were recruited via email, postal mail, and phone as available from an academic medical center in Milwaukee, Wisconsin. Focus group discussions were transcribed verbatim, reviewed by the study team, and coded based on recurring themes within and across interviews. Responses were analyzed by frequency of occurrence using qualitative computer software.

Results $\quad$ Five primary barriers to weight management were identified from focus groups: food choices, lifestyle changes, social support, locus of control, and health education. Based on participant reports, improvements to present practice and health literacy for patients may be merited. There was expressed interest by patients for being involved in future research and development of patient-centered interventions.

Conclusions This study provides support for the use of a community-based participatory research approach in determining appropriate considerations for weight management interventions suitable for this patient population. Future research should include stakeholders not included in this study, such as community organization leaders, and primary care physicians to develop a refined intervention targeting the primary barriers to weight management. (J Patient Cent Res Rev. 2018;5:287-297.)

Keywords weight management; obesity; women; community advisory board; community-based participatory research

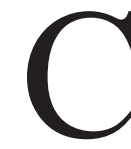
urrently, over one-third of adults in the United States are considered obese, with a significant increasing trend in the population occurring over the past decade. ${ }^{1,2}$ Obesity is a major public health problem and has been associated with multiple chronic diseases and comorbidities. ${ }^{3}$ People who are overweight

Correspondence: Owen Bowie, MPH, NWQ Building B, 2025 E. Newport Avenue, Milwaukee, WI 53211-2906 (obowie@uwm.edu) or obese have a much greater risk of developing multiple serious conditions, including cardiovascular disease, type 2 diabetes, myocardial infarction, chronic kidney disease, cancer, and hypertension, among others ${ }^{3,4}$ Annual medical spending attributable to obesity has been estimated at $\$ 149.4$ billion in 2014, with projected estimates quoting associated expenditures could rise $\$ 44$ billion- $\$ 66$ billion/year by 2030 given current trends. ${ }^{4,5}$

Wisconsin ranks $23^{\text {rd }}$ among U.S. states in adult obesity rate at $30.7 \%$, and trends indicate rates will continue to 
increase. ${ }^{6,7}$ In Milwaukee, the state's largest city, $61.3 \%$ of residents are considered overweight or obese. ${ }^{7}$ When stratifying the state by race, African Americans disproportionately represent higher rates of obesity (34.4\%) compared to Latinos (29.4\%) and whites $(24.6 \%){ }^{7}$ Estimates based on the Survey of the Health of Wisconsin (2008-2013) indicate that disparities across racial and ethnic groups are higher in Wisconsin than those observed nationally. ${ }^{8}$ Data from the survey indicate that upwards of $39.4 \%$ of Wisconsin adults are obese, with $54.9 \%$ of African Americans reporting a body mass index (BMI) of $30 \mathrm{~kg} / \mathrm{m}^{2}$ or more compared to $44.9 \%$ of Latinos and $38.9 \%$ of whites. ${ }^{8}$ According to a report by the Wisconsin Department of Health Services, disparities in obesity rates among women are even greater, with $40.8 \%$ of African American women, compared to $33.3 \%$ Latina and $22.4 \%$ white women, reported to be obese. ${ }^{7}$

In response to recent recommendations, there has been a shift in hospitals and health care systems to implement additional patient engagement and person-centered care. ${ }^{9}$ One strategy for facilitating patient engagement includes use of community advisory boards, which has been shown to improve both patient satisfaction and health outcomes through improved patient engagement in health care decisions. ${ }^{9}$ Community advisory boards use a community-based participatory research approach to engage patients in community-based interventions intended to reduce health disparities related to chronic disease. ${ }^{10}$ Current literature also supports the use of community-based participatory research in developing effective interventions, and the use of community advisory boards has been shown to work well for diseases that disproportionately affect minority communities. ${ }^{11}$

Despite evidence supporting these practices, a better understanding of potential weight management interventions remains needed for African American women. Limited research has included work identifying patient-centered outcomes or included patients in the planning of outcomes and weight management interventions. ${ }^{12}$ The inclusion of patient perspectives in treatment development and intervention delivery is crucial in addressing community health inequities..$^{12,13}$ Consequently, there is a need for including African American women in the planning of interventions that impact their own ability to appropriately manage their weight. As reported by Fink et al, patient-centered and culturally appropriate approaches to weight management and metabolic syndrome for women showed positive outcomes. ${ }^{14}$ Such an approach in the target population may effectively address gaps not otherwise included in previous weight management interventions. By engaging African American women in the community through semi-structured focus group interviews, the development of an effective community action plan for improved weight management among participants may be achieved.

The primary aim of the study presented herein was to assess the perceptions of Milwaukee-area African American women who were overweight or obese, using semi-structured focus groups in order to identify and explore barriers that inhibit weight management as well as potential community assets that might inform development of weight management strategies targeted toward African American women. Our secondary aim was to generate recommendations, based on the feedback provided, for developing a patient-centered weight management intervention designed specifically for African American women in the Milwaukee-area community.

We anticipate that approaches developed through this study will serve as a model for approaching weight management in health care settings within medically underserved communities in Milwaukee as well as other medically underserved communities with high rates of obesity.

\section{METHODS}

This study used semi-structured focus group interviews, qualitative analysis, and surveys designed to examine key issues and determine barriers to weight management success in an attempt to consider the perspectives of African American women who were overweight or obese. Semi-structured focus groups are the most commonly used interview format among qualitative research studies and are developed based on predetermined open-ended questions, with otherwise unplanned questions arising organically among the interviewer and interviewees. ${ }^{15,16}$

\section{Study Participants}

A total of 41 women participated in 1 of 3 focus group interviews, which were followed by a debriefing 
session held approximately 1 month after the focus group. The purpose of the debriefing session was to validate the themes that emerged through data analysis and allow each participant to contribute to the discussion. Individuals who participated in the focus groups were recruited from a local academic medical center via email, postal mail, and phone from July 2015 to September 2015, and all focus groups were completed by the end of October 2015.

Inclusion criteria were African American women with $\mathrm{BMI} \geq 30 \mathrm{~kg} / \mathrm{m}^{2}$ who lived in one of the following city of Milwaukee zip codes at the time of the study: 53233, $53205,53206,53212$, or 53204. These zip codes were selected a priori among the Milwaukee neighborhoods with the greatest disparities in health care access and weight control. The population of female patients who met these inclusion criteria were identified via the generation of a query using the i2b2 Cohort Discovery Tool (Clinical and Translational Science Institute [CTSI], Milwaukee, WI). Upon generating a list of patients, randomization was used to select women to invite to participate in the study. Identifiable data used in this study were gathered from CTSI's data warehouse, which is linked to $i 2 b 2$.

All participants in this study provided informed consent to participation in audio-recorded focus group interviews, survey completion, and participation in the follow-up debriefing session. This study was approved by the institutional review board of the Medical College of Wisconsin (Milwaukee, WI), through which the study was conducted.

\section{Focus Groups}

Focus group interviews were conducted by members of the study team with the goal of addressing 4 key themes: 1) identify barriers that inhibit the discussion and management of weight issues; 2) recognize community assets that improve health outcomes; 3) explore the role of locus of control on weight management; and 4) identify the important people and activities that aid in weight management strategies targeted toward African American women. Focus group interviews were scheduled to last approximately 90 minutes and were audio-recorded and subsequently transcribed. The facilitator began each focus group by explaining that the aims of focus groups and debriefing sessions were to encourage open discussion that facilitated participants to collaboratively explore ideas. ${ }^{15,16}$

Following each focus group, participants were provided with surveys designed to examine key issues and to expose barriers to success, as well as gauge their willingness to participate in a patient expert advisory council (ie, a community advisory board). The council would be designed to have patients work alongside community group leaders and physicians to develop a patient-centered intervention, targeting obesity/ overweight disparities among African American women within Milwaukee.

After the study team completed an initial analysis of the interview data, a short debriefing session with identified themes from the focus group interviews was prepared and shared with a subset of participants who had participated in the focus groups. Participants were offered one $\$ 25$ gift card to compensate them for their time spent participating in the initial focus group and survey, and one $\$ 25$ gift card to compensate them for participation in the debriefing discussion.

\section{Qualitative Data Analysis}

Focus group sessions were audio-recorded and subsequently transcribed verbatim. Following completion of focus groups and debriefing sessions, focus group transcripts were qualitatively analyzed by a single member of the study team using computerassisted qualitative data analysis software (ATLAS. ti 6.0, Scientific Software Development GmbH, Berlin, Germany) to determine the frequency of the coded themes (selected from initial data analysis and validation), within and across focus groups (Table 1). Data were analyzed by way of the following: 1) each transcript was read from start to finish; 2) key words and phrases that stood out were underlined; and 3) electronic comments about tentative ideas for topics, along with noticeable themes and patterns, were added to the transcripts. A report with identified themes from the interviews was created and reviewed by the study team to contextualize results. ${ }^{13}$

Recurring ideas within and across each interview were used by the 3-member consensus coding team to establish a final list of emerging codes and themes. Next, relationships among ideas and themes were examined to create theoretical concepts. ${ }^{17}$ After the study team 
Table 1. Qualitative Codes Applied to Focus Group Transcript Analysis

\begin{tabular}{|c|c|}
\hline Code Name & Description \\
\hline \multicolumn{2}{|l|}{ INDIVIDUAL } \\
\hline Enjoyable activities & Engaging in activities enjoyed by the participant \\
\hline Barriers to PA: scheduling & Scheduling conflicts that make it difficult to engage in PA \\
\hline Comorbidities & Describes chronic conditions and other chronic disease and/or screenings \\
\hline Health education & Learning diet and exercise-related content \\
\hline Food choices & Learning to make healthy choices given the food available \\
\hline Emotional eating & How stress may lead to emotional eating \\
\hline Individualized weight management plans & Weight management approaches tailored to each individual \\
\hline Genetic memory & Genetic predisposition to behaviors and disease outcomes \\
\hline Health insurance & Concerns around health insurance and premiums \\
\hline Locus of control & Patient's ability to control weight \\
\hline \multicolumn{2}{|l|}{ INTERPERSONAL } \\
\hline Social support & Social support to begin and maintain activity \\
\hline Accountability & Remaining accountable for program participation \\
\hline Barriers to PA: family & Familial factors that impede PA \\
\hline Barriers to PA: neighborhood factors & Difficulty engaging in PA based on where participant lives \\
\hline Culturally appropriate food & Relevance and importance of cultural foods \\
\hline Holistic health & Focusing on social determinants of health, rather than simply the individual \\
\hline Consistency & $\begin{array}{l}\text { - Expectation that programs will continuously operate } \\
\text { - Expectation that classes will be taught on a specific day at a designated time }\end{array}$ \\
\hline Body image & Individual and cultural perceptions of body image \\
\hline Weight loss incentives & Incentives for losing weight \\
\hline Family food preferences & Obtaining food and preparing meals preferred by the family \\
\hline \multicolumn{2}{|l|}{ ORGANIZATIONAL } \\
\hline Change in staff & Difficulty in staff retention \\
\hline Lifestyle changes & Thinking broadly about diet and exercise \\
\hline Routine & Incorporating activities into lifestyle \\
\hline Culturally designed programs & Describes how culture is embedded in programs \\
\hline Weight loss models & Components of commercial weight loss models/approaches \\
\hline Social service resources & $\begin{array}{l}\text { - Availability of material and resources regarding programs, food stamps, WIC, etc } \\
\text { - Connecting individuals to resources }\end{array}$ \\
\hline Patient-physician relationship & Positive or negative interactions patients have with providers \\
\hline \multicolumn{2}{|l|}{ COMMUNITY } \\
\hline Behavioral stigma (or reframing weight loss) & Easier to discuss "healthy living" than "weight management" \\
\hline Community gardens & Importance of community gardens for healthy eating \\
\hline Empowerment & Empowering people/patients/participants to be more engaged in their health \\
\hline \multicolumn{2}{|l|}{ PUBLIC POLICY } \\
\hline Neighborhood food access & Access to food including fast food restaurants, corner stores, food pantries, etc \\
\hline Food pricing & Affordability of healthier food options \\
\hline \multicolumn{2}{|l|}{ OTHER } \\
\hline Other & Includes items that are notable but not present in the existing list of items above \\
\hline
\end{tabular}

PA, physical activity; WIC, Special Supplemental Nutrition Program for Women, Infants, and Children. 
completed the initial analysis of the interview data, a brief report was prepared with themes identified from the interviews. This report was shared with a subset of participants who had previously participated in an interview to ensure validity and accuracy of results. ${ }^{18,19}$

\section{RESULTS}

\section{Participant Characteristics}

Of the 41 women who participated in the focus groups, 40 responded to a follow-up survey. One participant did not report demographic information for employment or marital status. All women identified as African American and had an average BMI of $39.35 \mathrm{~kg} / \mathrm{m}^{2}$ based on selfreported weight and height. The majority of women who participated were $45-64$ years of age $(67.5 \%)$, with a family/household income less than $\$ 29,000$ (72.5\%). Participants also were most likely to be married (25.6\%), have completed some college (40\%), and be employed for wages $(41.0 \%)$. Participants represented all but one zip code, 53204, which provided zero participants. Of the zip codes sampled, $70 \%$ of participants were from $53206(\mathrm{n}=12,30 \%)$ or $53212(\mathrm{n}=16,40 \%)$. In total, 29 of the 41 women expressed interest in joining a patient expert advisory council. Additional demographic characteristics are presented in Table 2.

\section{Recurring Themes}

Data gathered from patients evidencing key themes emerging from focus group interviews are summarized in Table 3. The 5 most influential themes on participants' weight management presented across all focus groups included food choices, lifestyle changes, social support, locus of control, and health education. Illustrative quotes related to primary recurring themes are presented in Table 4.

The frequency of predominating themes within individual focus groups were slightly different. In focus group 1, the top 5 quoted codes were food choices, patientphysician relationship, locus of control, social support, and family-associated barriers to physical activity. In focus group 2, the top 5 codes were social support, locus of control, lifestyle changes, holistic health, and family food preferences. In focus group 3, the top 5 codes were food choices, lifestyle changes, health education, social support, and locus of control. However, predominating themes across all groups included the implications of food choices, presence or lack of social support, and making appropriate lifestyle changes.
Table 2. Participant Demographics

\begin{tabular}{|c|c|}
\hline Demographic Characteristic & n (\%) \\
\hline \multicolumn{2}{|l|}{ Age, years } \\
\hline$<18$ & $0(0)$ \\
\hline $18-24$ & $1(2.5)$ \\
\hline $25-34$ & $6(15.0)$ \\
\hline $35-44$ & $5(12.5)$ \\
\hline $45-54$ & $15(37.5)$ \\
\hline $55-64$ & $12(30.0)$ \\
\hline $65-74$ & $1(2.5)$ \\
\hline$>75$ & $0(0)$ \\
\hline \multicolumn{2}{|l|}{ Education } \\
\hline Less than high school & $4(10.0)$ \\
\hline High school graduate & $10(25.0)$ \\
\hline Some college & $16(40.0)$ \\
\hline Technical diploma & $3(7.5)$ \\
\hline 2-year degree & $2(5.0)$ \\
\hline 4-year degree & $3(7.5)$ \\
\hline Professional degree & $1(2.5)$ \\
\hline Doctorate & $0(0)$ \\
\hline Other & $1(2.5)$ \\
\hline \multicolumn{2}{|l|}{ Income } \\
\hline$<\$ 10,000$ & $12(30.0)$ \\
\hline$\$ 10,000-\$ 19,000$ & $9(22.5)$ \\
\hline$\$ 20,000-\$ 29,000$ & $8(20.0)$ \\
\hline$\$ 30,000-\$ 39,000$ & $4(10.0)$ \\
\hline$\$ 40,000-\$ 49,000$ & $4(10.0)$ \\
\hline$\$ 50,000-\$ 59,000$ & $2(5.0)$ \\
\hline$\$ 60,000-\$ 69,000$ & $0(0)$ \\
\hline$\$ 70,000-\$ 79,000$ & $0(0)$ \\
\hline$\$ 80,000-\$ 89,000$ & $0(0)$ \\
\hline$\$ 90,000-\$ 99,999$ & $1(2.5)$ \\
\hline$>\$ 100,000$ & $0(0)$ \\
\hline \multicolumn{2}{|l|}{ Marital status } \\
\hline Married & $10(25.6)$ \\
\hline Widowed & $4(10.3)$ \\
\hline Divorced & $5(12.8)$ \\
\hline Separated & $1(2.6)$ \\
\hline Single & $19(8.7)$ \\
\hline \multicolumn{2}{|l|}{ Employment status } \\
\hline Employed for wages & $16(41.0)$ \\
\hline Self-employed & $2(5.1)$ \\
\hline Unemployed, looking for work & $6(15.4)$ \\
\hline Unemployed, not looking for work & $0(0)$ \\
\hline Retired & $5(12.8)$ \\
\hline Student & $1(2.6)$ \\
\hline Military & $0(0)$ \\
\hline Homemaker & $1(2.6)$ \\
\hline Unable to work & $8(20.5)$ \\
\hline \multicolumn{2}{|l|}{ Zip code } \\
\hline 53233 & $4(10.0)$ \\
\hline 53205 & $8(20.0)$ \\
\hline 53206 & $12(30.0)$ \\
\hline 53212 & $16(40.0)$ \\
\hline 53204 & $0(0)$ \\
\hline Other & $0(0)$ \\
\hline
\end{tabular}


Table 3. Recurring Themes From Focus Group Discussions

\begin{tabular}{|c|c|c|c|c|}
\hline \multirow[b]{2}{*}{ Theme Name } & \multicolumn{4}{|c|}{ Number of Quotations } \\
\hline & All & $\begin{array}{l}\text { Focus } \\
\text { Group } 1\end{array}$ & $\begin{array}{l}\text { Focus } \\
\text { Group } 2\end{array}$ & $\begin{array}{l}\text { Focus } \\
\text { Group } 3\end{array}$ \\
\hline Food choices & 49 & 22 & 1 & 26 \\
\hline Lifestyle changes & 30 & 6 & 6 & 18 \\
\hline Social support & 29 & 11 & 8 & 10 \\
\hline Locus of control & 28 & 13 & 7 & 8 \\
\hline Health education & 21 & 4 & 1 & 16 \\
\hline Holistic health & 19 & 8 & 5 & 6 \\
\hline Patient-physician relationship & 16 & 14 & 1 & 1 \\
\hline Family food preferences & 15 & 7 & 4 & 4 \\
\hline Barriers to PA: family & 12 & 9 & 1 & 2 \\
\hline Barriers to PA: neighborhood factors & 8 & 6 & 2 & 0 \\
\hline
\end{tabular}

$P A$, physical activity.

Food Choices: Participants emphasized the importance of daily food choices in successfully losing weight (Table 4). Participants also discussed the influence of family factors and busy schedules on typical food choices, with the most readily available and accessible foods often being less healthy options.

"Most people who work and have children, you get off of work, it's easy to stop through a drive-thru versus coming home and cooking."

Lifestyle Changes: Participants discussed the importance of lifestyle change, with emphasis on personal choices and developing new eating habits, towards better weight management (Table 4). Others spoke to the difficulties of making necessary lifestyle changes based on social environmental factors. Participants also provided examples of how small lifestyle changes, such as incorporating physical activity as a healthy way to cope with stress rather than eating, can have a positive influence on weight management.

"When I used to get stressed, I used to eat, eat, eat, eat, eat, but now I get up, get me a couple of bottles of water, and walk."

Social Support: Social support was also a primary recurring theme across focus groups, with women most commonly referencing family and friends as influential key individuals (Table 4). Some of the barriers that the women identified as restrictive to appropriate weight management included a lack of social support; several women mentioned that they may potentially benefit from a regular form of community focus group.

"I think a support group would be very nice because I need that."

Additionally, social support in relation to family dynamics and obligations served as important barriers. Providing meals for the family while incorporating healthy food choices were among the barriers noted by participants. Other important activities included walking, which often co-occurred with themes of social support. The women also addressed neighborhood safety as a concern, stating "safety is an issue," particularly as a barrier to walking activity in their neighborhoods alone or at night. One woman cited her experience with a physical altercation with a man during the day while attempting to exercise.

Locus of Control: Locus of control was identified as an individual's internal ability to control one's weight and was discussed by participants throughout groups, with an emphasis on internal locus of control and the role of the individual in successful weight management (Table 4). Other participants expressed feeling frustrated about their inability to make changes despite behavioral changes.

"I get frustrated when I try to do the right things and they still don't work. I try to follow this diabetic diet ... no matter what I do, my sugar doesn't go away." 
Table 4. Illustrative Quotes Related to Primary Recurring Themes

\begin{tabular}{|c|c|c|}
\hline Themes & $\mathbf{n}$ & Quotes \\
\hline Food choices & 49 & $\begin{array}{l}\text { "Most people who work and have children, you get off of work it's easy to stop through a } \\
\text { drive-thru versus coming home and cooking." } \\
\text { "Those are like choices I have to make. Do I want to feel bad? Or do I want to feel } \\
\text { healthy?" } \\
\text { "A lot of people have a problem with [inaudible] eating the same old way that they've } \\
\text { been eating since they've been able to eat. It's taste. They have a problem with the } \\
\text { taste because certain things will change the taste of your food. So they have a problem } \\
\text { with changing how things cook, how they eat." }\end{array}$ \\
\hline Lifestyle changes & 30 & $\begin{array}{l}\text { "Good eating habits. We have to form good eating habits and it has to be something that } \\
\text { we can do." } \\
\text { "I eat like I'm from the South. It's hard to change over, and you're constantly in that } \\
\text { environment." } \\
\text { "When I used to get stressed, I used to eat, eat, eat, eat, eat, but now I get up, get me a } \\
\text { couple of bottles of water, and walk." }\end{array}$ \\
\hline Social support & 29 & $\begin{array}{l}\text { "It doesn't really work when one person in the house is trying to manage their weight, } \\
\text { eating healthy if everybody else is [not] eating [healthy]." } \\
\text { "My husband tries to monitor what I'm doing and what I'm eating ... I know he's trying to } \\
\text { be supportive, but his method is not working. It's too degrading. ... Some people don't } \\
\text { understand what it actually entails." } \\
\text { "I think I just need somebody to hang out with and go with me, and we just probably do } \\
\text { something together. Versus me being by myself." } \\
\text { "Sometimes you go to the mall and walk. Go to the mall, take a friend." }\end{array}$ \\
\hline Locus of control & 28 & $\begin{array}{l}\text { "So some of this stuff is on the individual to make the choices to change. And if an } \\
\text { individual doesn't want to change, it's never going to work." } \\
\text { "I get frustrated when I try to do the right things and they still don't work. I try to follow } \\
\text { this diabetic diet ... no matter what I do, my sugar doesn't go away." } \\
\text { "I think it's important, too, to have a mindset, a positive mindset first of all in order to } \\
\text { know about what you want to do as far as your body, exercise. If you're not thinking right } \\
\text { in your head and thinking this is an important thing to do, you're not going to do it. You're } \\
\text { going to always think about, oh well, I see that, this candy, this cake. I just do it. But you } \\
\text { got to think about what's going on in your body. That's so important now." }\end{array}$ \\
\hline Health education & 21 & $\begin{array}{l}\text { "I also need more informational support personally." } \\
\text { "I go to the dietitian. They go over the meal plan and everything. Everything I know that I } \\
\text { should be eating and the portion size." } \\
\text { "All of a sudden I just started gaining weight, gaining weight and right to this day my } \\
\text { doctor can't even tell me why. So knowing, having that information will probably help." }\end{array}$ \\
\hline
\end{tabular}

Health Education: Relationships with health providers in relation to health education and patient-physician relationships also were part of focus group discussions. The participants often reported that the education offered by providers was often limited or inadequate to facilitate suggested lifestyle change.

"Whenever I go to my doctor that's the first thing they say is, 'You're overweight.' I already know that."
Participants emphasized the importance of learning appropriate diet and exercise information, and some of the participants discussed the benefits of meeting with a dietitian to discuss diet and meal plan information (Table 4).

\section{Holistic Health}

Although not a primary recurring topic of discussion within the group, social determinants were referenced 
throughout each group in relation to neighborhood food accessibility and safety as barriers to engaging in healthy weight management behavior. For example, one participant stated:

"If you ever notice every half a block there's a McDonald's, Wendy's, Popeye's." and "I also think that it has to do especially in this area for those who unfortunately don't have transportation. I think the fact that we live in a food desert probably adds to that. We don't have accessibility to fresh food, fresh fruit, fresh vegetables in the area."

\section{DISCUSSION}

Following qualitative analysis of focus group results, some of the most surprising findings were the differences seen in the frequency of central themes across groups. Within focus group 1, the emphasis on the patient-physician relationship was much greater, resulting in 14 quotations compared to the single quotation in each of the other corresponding focus groups. Additionally, the emphasis on food choices among women were strong in focus groups 1 and 3 but rather weak in focus group 2, with only one quotation compared to the 22 and 26 quotations within 1 and 3 , respectively.

The differences in the distribution of the frequencies of these quotations across interview groups may be explained by the variable composition of the groups themselves. The groups were provided at different times and dates that may have influenced the distribution of the types of individuals that attended each group as well as the resulting frequencies of themes discussed. Although there were some differences in the frequencies of quotations across focus groups, the important themes that were discussed within each group were similar with respect to other qualitative codes.

Another recurring theme among women included food choices and social support. These themes were reiterated by participants throughout discussions and may be explained by the importance of social support in facilitating lifestyle changes such as healthier food choices.

The importance of the patient-physician relationship was evident among participants. Barriers to communication with physicians included perceived beliefs that physicians did not care about their well-being and that physicians approached weight in ways that were perceived to be ineffective and dismissive. Participants felt that most physicians did not spend enough time with them to provide the needed information for weight loss and management. This related strongly to health education, which the women felt was not properly provided to them by their physician, particularly with respect to the types of lifestyle changes necessary beyond the response of needing a healthier diet and increased exercise. Alternatively, from the physician's perspective, studies have referenced physicians feeling they had insufficient training to have meaningful and impactful conversations regarding weight management with patients. ${ }^{20}$ Additionally, physicians often perceive patients as lacking motivation to address their weight rather than considering potential social and ecological barriers to proper weight management. ${ }^{20}$ Such discrepancies present in perceptions between patients and physicians builds a picture of present deficits in patient-provider communication, and potentially highlights areas for targeted improvement.

Potential recommended weight interventions might include those that target the primary themes referenced by focus group participants. These may include community education programs to increase knowledge of strategies to incorporate healthy food choices while remaining mindful of financial restrictions..$^{21}$ Support of community gardens and public health policy initiatives that increase accessibility to healthy food options within communities may be viable approaches that also facilitate more appropriate food choices. ${ }^{22}$ Other strategies also may increase the general health literacy within the community. ${ }^{23}$ Approaches that target present practice among providers who treat African American women who are overweight or obese may be merited. ${ }^{21}$

The participants expressed interest in a community focus group that would meet regularly and discuss educational materials, in addition to providing social support and encouragement in meeting their individualized weight management goals. Lifestyle modification programs facilitated within primary care settings, such as the one outlined by Fink et al, 
have demonstrated the benefits of a patient-centered approach towards addressing metabolic syndrome and obesity among women. ${ }^{14}$ Although individually such strategies have been shown to provide beneficial outcomes in reducing disparities in obesity within communities, a multidisciplinary and coordinated approach is needed to create sustainable community change. Future research is needed to clarify the thoughts and feelings of this community and ensure appropriate representation.

This project is part of a larger group of studies that considers the perspectives of patients, community health advocates, and primary care physicians who treat overweight or obese patients through semi-structured interviews and surveys designed to examine key issues and to expose barriers to success. Emerging themes identified during this study will be used by a patient expert advisory council to assist in the development of a patient-centered intervention designed specifically for African American women. Based on results of the follow-up survey provided to participants in the study, many of the women who participated $(n=29)$ expressed interest in potentially joining the council. The interest expressed by patients for involvement in future research is promising and supports the feasibility of developing a council with the eventual goal of designing and implementing a patient-centered approach specific to this patient population.

Future research is needed to determine how to implement multicomponent weight loss interventions that include partnerships between primary care provider clinics and communities to maximize population-specific weight loss and management. ${ }^{24}$ We anticipate that the information gained by examining the perceptions of patients, community organization leaders, and physicians in unison will yield rich data that may guide the planning, implementation, and evaluation of similar programs within other patient populations. Such an approach also may serve as a model for developing weight management interventions within health care settings amid medically underserved communities.

\section{Limitations}

The limitations of this study include those consistent among most qualitative studies. Namely, that data collected was based on the subjective perceptions of participants and findings may not be generalizable. Since recruitment of study participants were randomly selected from a present and past patient database of the Medical College of Wisconsin, there is the potential for selection bias and some members within the community of interest may have been inadvertently excluded from study recruitment. Additionally, limitations remain with regards to the number of focus groups facilitated and total study size. Strengths of the study design include a patient-centered approach to elucidate the perceptions of patients on the primary factors that influence their ability to be successful in weight management while facilitating a semi-structured discussion.

Further research requires incorporation of key stakeholders not otherwise included in this study, such as community organization leaders and primary care physicians who treat the study population. Elucidating the perspectives of other community stakeholders and their potential roles in developing an effective and sustainable intervention for weight management among African American women in the community is needed. Furthermore, consideration for the inclusion of perspectives among other relevant stakeholders, including various medical specialties, nutritionists, community health workers, and public health promotion specialists, among others, is merited. Future studies should emphasize the collaborative inclusion of study participants and community members in analysis of study findings and intervention development wherever possible to ensure an efficacious approach for weight management relevant for the community.

\section{CONCLUSIONS}

The key barriers identified by group participants across focus groups included social support, lifestyle changes, locus of control, health education, and food choices. Based on these findings, the most effective approaches leading to patient engagement and sustainable healthy behaviors will likely include a combination of efforts at multiple levels, with particular consideration of social determinates and the interconnected recurring themes presented by study participants. Further incorporation of community stakeholder involvement throughout the process would be advised to contextualize results from this study and promote lasting community change. 
Continuation of research presented in this study will include patients, community organization leaders, and physicians via the creation of a patient expert advisory council to assist in the development of patient-centered interventions for weight management suitable for local African American women, who present the greatest disparities in obesity rates.

\section{Patient-Friendly Recap}

- Focus groups revealed that the primary barriers to weight management among overweight/obese African American women in the Milwaukee area include food choices, lifestyle changes, social support, locus of control, and health education.

- Results indicated a local need to improve the provision of health education to this patient population.

- Engaging patients through the authors' participatory research approach effectively yielded qualitative information related to weight management.

- Including additional stakeholders, such as community leaders and physicians, in future studies may help refine interventions targeting weight loss barriers for African American women.

\section{Acknowledgments}

The study team would like to acknowledge the participation and engagement of the women involved in focus groups throughout this study and thank them for providing their knowledge and personal experiences on weight management difficulties currently present in the Milwaukee community.

\section{Author Contributions}

Study design: all authors. Data acquisition or analysis: all authors. Manuscript drafting: Bowie. Critical revision: Bowie, Fink, Gill, Walker, Cisler.

\section{Conflicts of Interest}

None.

\section{Funding Sources}

This project was funded by a Patient-Centered Outcomes Research Program seed grant, sponsored by the Medical College of Wisconsin (Milwaukee, WI).

\section{References}

1. Hales CM, Carroll MD, Fryar CD, Ogden CL. Prevalence of obesity among adults and youth: United States, 2015-2016. NCHS Data Brief. 2017;(288):1-8.

2. Ogden CL, Carroll MD, Fryar CD, Flegal KM. Prevalence of obesity among adults and youth: United States, 2011-2014. NCHS Data Brief. 2015;(219):1-8.

3. The GBD 2015 Obesity Collaborators. Health effects of overweight and obesity in 195 countries over 25 years. $N$ Engl J Med. 2017;377:13-27. CrossRef

4. Kim DD, Basu A. Estimating the medical care costs of obesity in the United States: systematic review, meta-analysis, and empirical analysis. Value Health. 2016;19:602-13. CrossRef

5. Wang YC, McPherson K, Marsh T, Gortmaker SL, Brown M. Health and economic burden of the projected obesity trends in the USA and the UK. Lancet. 2011;378:815-25. CrossRef

6. Centers for Disease Control and Prevention. Behavioral risk factor surveillance system: survey data \& documentation. Page last updated 2018 Aug 30. https:/www.cdc.gov/brfss/ data_documentation/index.htm. Accessed September 2, 2018.

7. Liebhart JL,Wegner MV, Pesik MJ. Obesity, nutrition, and physical activity in Wisconsin (No. P-00008). Madison, WI: Wisconsin Department of Health Services, Wisconsin Partnership for Activity and Nutrition, December 2008.

8. Eggers S, Remington PL, Ryan K, Nieto J, Peppard P, Malecki K. Obesity prevalence and health consequences: findings from the survey of the health of Wisconsin. WMJ. 2016;115:238-43.

9. Haycock C, Wahl C. Achieving patient and family engagement through the implementation and evolution of advisory councils across a large health care system. Nurs Adm Q. 2013;37:242-6. CrossRef

10. Newman SD, Andrews JO, Magwood GS, Jenkins C, Cox MJ, Williamson DC. Community advisory boards in community-based participatory research: a synthesis of best processes. Prev Chronic Dis. 2011;8:A70.

11. Strauss RP, Sengupta S, Quinn SC, et al. The role of community advisory boards: involving communities in the informed consent process. Am J Public Health. 2001;91:1938-43. $\underline{\text { CrossRef }}$

12. Miller ST, Akohoue SA, Brooks MA. Identification of patientcentered outcomes among African American women with type 2 diabetes. Diabetes Res Clin Pract. 2014;106:487-90. CrossRef

13. Fleurence R, Selby JV, Odom-Walker K, et al. How the Patient-Centered Outcomes Research Institute is engaging patients and others in shaping its research agenda. Health Aff (Millwood). 2013;32:393-400. CrossRef

14. Fink JT, Havens KK, Schumacher JA, et al. Impact of the Heart WATCH program on patients at risk of developing metabolic syndrome, prediabetes or cardiovascular disease. J Patient Cent Res Rev. 2015;2:56-63. CrossRef

15. DiCicco-Bloom B, Crabtree BF. The qualitative research interview. Med Educ. 2006;40:314-21. CrossRef

16. Stewart DW, Shamdasani PN. Focus groups: theory and practice. Applied Social Research Methods Series, Volume 20. Newbury Park, CA: Sage Publications, 1990.

17. Kusch J. Learning experiences of university biology faculty: a qualitative pilot study. J Coll Sci Teach. 2016;45(6). $\underline{\text { CrossRef }}$ 
18. Kallio H, Pietilä AM, Johnson M, Kangasniemi M. Systematic methodological review: developing a framework for a qualitative semi-structured interview guide. J Adv Nurs. 2016;72:2954-65. CrossRef

19. Merriam SB, Tisdell EJ. Qualitative Research: A Guide to Design and Implementation, Fourth Edition. San Francisco, CA: Jossey-Bass, 2016.

20. Walker RE, Kusch J, Fink JT, et al. Facilitating factors and barriers to weight management in women: physician perspectives. J Patient Cent Res Rev. 2018;5:18-27. CrossRef

21. Dunneram Y, Jeewon R. Healthy diet and nutrition education program among women of reproductive age: a necessity of multilevel strategies or community responsibility. Health Promot Perspect. 2015;5:116-27. CrossRef

22. Draper C, Freedman D. Review and analysis of the benefits, purposes, and motivations associated with community gardening in the United States. $J$ Community Pract. 2010;18:458-92. CrossRef
23. de Wit L, Fenenga C, Giammarchi C, et al. Community-based initiatives improving critical health literacy: a systematic review and meta-synthesis of qualitative evidence. $B M C$ Public Health. 2017;18(1):40. CrossRef

24. Hartmann-Boyce J,Johns DJ, Jebb SA, SummerbellC,Aveyard P; Behavioural Weight Management Review Group. (2014). Behavioural weight management programmes for adults assessed by trials conducted in everyday contexts: systematic review and meta-analysis. Obes Rev. 2014;15:920-32. $\underline{\text { CrossRef }}$

(C) 2018 Aurora Health Care, Inc. 